\title{
Evaluation of the mitochondrial respiration of cardiac myocytes in rats submitted to mechanical bile duct obstruction ${ }^{1}$
}

\author{
Avaliação da respiração mitocondrial de miócitos cardíacos em ratos ictéricos \\ sumetidos à obstrução do ducto biliar
}

\author{
Rafael Kemp ${ }^{\text {I }}$, Orlando de Castro-e-Silva ${ }^{\text {II }}$, José Sebastião dos Santos ${ }^{\text {III }}$, Ajith Kumar Sankarankutty ${ }^{\text {IV }}$, Rodrigo Borges \\ Correa $^{\text {v }}$, Caroline Floreoto Baldo ${ }^{\text {II }}$, Maria Elisa Jordani Souza ${ }^{\text {VII }}$, Maria Cecilia Jordani ${ }^{\mathrm{VII}}$ \\ MD, Assistant, Division of Digestive Surgery, Department of Surgery and Anatomy, Ribeirão Preto Faculty of Medicine, University of \\ São Paulo, Brazil. \\ II Full Professor and Head Division of Digestive Surgery, Department of Surgery and Anatomy, Ribeirão Preto Faculty of Medicine, \\ University of São Paulo, Brazil. \\ III PhD, Professor, Division of Digestive Surgery, Department of Surgery and Anatomy, Ribeirão Preto Faculty of Medicine, University of \\ São Paulo, Brazil. \\ Iv PhD, Professor, Division of Digestive Surgery, Department of Surgery and Anatomy, Ribeirão Preto Faculty of Medicine, University of \\ São Paulo, Brazil. \\ v Fellow PhD degree, Assistant, Division of Digestive Surgery, Department of Surgery and Anatomy, Ribeirão Preto Faculty of Medicine, \\ University of São Paulo, Brazil. \\ vI Veterinarian Physician, Fellow PhD degree, Department of Surgery and Anatomy, Ribeirão Preto Faculty of Medicine, University of São \\ Paulo, Brazil. \\ VII Biochemist of Laboratoty of Biochemistry of Liver Transplantation Unit of the Departament of Surgery and Anatomy, Ribeirão Preto \\ Faculty of Medicine, University of São Paulo, Brazil. \\ VIII Biochemist of Laboratory of Biochemistry of Liver Transplantation Unit the Surgery Department of Surgery and Anatomy, Ribeirão \\ Preto Faculty of Medicine, University of São Paulo, Brazil.
}

\section{ABSTRACT}

Purpose: The objective of the present study was to evaluate the capacity of the myocardium for energy production by the analysis of mitochondrial respiration in rats with jaundice submitted to bile duct ligature. Methods: Sixteen male Wistar rats were divided into 2 Groups: Group SO submitted to nontherapeutic laparotomy (sham operation) and Group IC (icteric group) submitted to bile duct ligature. After 7 days, laparotomy was again performed in all animals for cardiac muscle extraction and analysis. Mitochondrial oxygen consumption was determined by stage 3 velocity and stage 4 velocity. The respiratory control ratio (RCR) was obtained by the ratio of stage 3 to stage 4 velocity. Statistical analysis was performed by the Mann-Whitney test, with the level of significance set at $5 \%(p<0.05)$. Results: Statistical analysis revealed a significant drop in oxygen consumption during stage 3 mitochondrial respiration in group IC compared with SO, whereas the values obtained during stage 4 were basically identical for the two groups. Likewise, RCR values exhibited a significant reduction. Conclusion: The cellular respiration of the "jaundiced heart" is depressed. This was demonstrated by the reduced capacity of cardiac mitochondria to consume oxygen and synthesize ATP, supporting the idea of a latent cardiac impairment responsible for the hemodynamic decompensation occurring during cholestasis.

Key words: Obstructive Jaundice. Heart Failure. Shock. Mitochondria.

\section{RESUMO}

Objetivo: A proposta deste trabalho é avaliar a capacidade de produção energética do miocárdio mediante análise da respiração mitocondrial em ratos ictéricos submetidos à ligadura do ducto biliar. Métodos: Foram utilizados 16 ratos Wistar machos divididos em 2 Grupos: Grupo SO, os quais foram submetidos à Laparotomia branca e Grupo IC, os quais sofreram ligadura do ducto biliar para o desenvolvimento de icterícia obstrutiva. Todos os animais após 7 dias de cirurgia foram submetidos à nova laparotomia para extração e análise do músculo cardíaco. $\mathrm{O}$ consumo de oxigênio pelas mitocôndrias foi determinado pela velocidade do estado 3 e velocidade do estado 4 . A razão do controle respiratório (RCR) foi obtida pela relação entre as velocidades dos estados 3 e 4 . A análise estatística foi feita pelo teste de Mann-Whitney com nível de signifícância de $5 \%(\mathrm{p}<0.05)$. Resultados: Observou-se queda estatisticamente significante nos valores do consumo de oxigênio do estado 3 da respiração mitocondrial no grupo IC em relação ao SO, no entanto os valores para estado 4 permaneceram basicamente inalterados entre os grupos. Os valores de RCR entre os grupos também apresentaram diminuição significativa. Conclusão: A respiração celular do 'coração ictérico' está deprimida em decorrência da redução da capacidade da mitocôndria cardíaca em consumir oxigênio e sintetizar ATP, o que pode contribuir para a disfunção cardiovascular na vigência da colestase.

Descritores: Icterícia Obstrutiva. Insuficiência Cardíaca. Choque. Mitocôndria.

1. Work performed in the Experimental Surgery Division, Department of Surgery and Anatomy, Ribeirão Preto Faculty of Medicine,

University of São Paulo, Brazil. 


\section{Introduction}

Obstructive jaundice secondary to extrahepatic biliary obstruction is a common clinical condition caused by biliary lithiasis, traumatic and inflammatory stenosis, extrinsic compression, and tumors in the biliary tree, papilla, pancreas and duodenum. ${ }^{1}$

Surgery performed to resolve extrahepatic biliary obstruction continues to be associated with a high morbimortality index. ${ }^{2}$

Patients with obstructive jaundice, besides having a reduced functional hepatic reserve, frequently develop postoperative complications such as hypotension and acute renal failure. ${ }^{3,4}$

A review of different series revealed a general mortality rate of 16 to $18 \%$ in patients submitted to surgery because of obstructive jaundice. Acute renal failure occurs in approximately 8 to $10 \%$ of these individuals, this being a factor that contributes to the mortality of 70 to $80 \%$ of these patients. ${ }^{2,5}$ The main cause of these rates resides in the greater susceptibility of patients with obstructive jaundice to postoperative shock and renal insufficiency. Experimental studies performed on animals with jaundice have demonstrated pronounced arterial hypotension and an exacerbated hypotensive response to hemorrhage. A possible explanation for this phenomenon may be the fact that obstructive jaundice causes peripheral vasodilatation and a refractory response to vasoactive agents. ${ }^{6}$

Clinical observations of patients with obstructive jaundice have demonstrated that bile salts exert negative inotropic and chronotropic effects on the cardiac muscle. Green and Better, ${ }^{5}$ in a study on dogs submitted to choledochocaval anastomosis, observed a reduction in left ventricular performance evidenced by a decrease of maximum peak pressure of the left ventricle, a prolonged pre-ejection period and left ventricular ejection time, as well as no alteration of systolic interval after ouabain administration, demonstrating the refractory characteristic of the "jaundiced heart" to the inotropic effects of digitalis. On the basis of these results, the authors proposed that patients presenting obstructive jaundice had a lingering cardiac dysfunction disguised by the reduced systemic vascular resistance. Thus, they were more predisposed to postoperative hemodynamic dysfunction caused by frequently observed conditions such as endotoxemia, sepsis, peripheral vasodilatation and volemic depletion. ${ }^{5,7}$

Literature reports have described a myocardiopathy caused by obstructive jaundice, though the exact cellular mechanism of this abnormality is still not fully understood. Some data have indicated intracellular glycogen depletion and deficient energy metabolism of cardiac myocytes as causes. ${ }^{8}$

Considering these features, the purpose of the present study was to evaluate the integrity of cardiac myocyte energy production in jaundiced rats submitted to bile duct ligature by determining stage 3 and 4 mitochondrial oxygen consumption velocity and the respiratory control ratio (RCR).

\section{Methods}

Sixteen male Wistar rats weighing 250 to $300 \mathrm{~g}$, obtained from the Central Animal house of the Ribeirão Preto Campus - USP, were divided into 2 experimental groups:
- Group “SO”' (Sham Operation): N=9 animals submitted to nontherapeutic laparotomy with abdominal cavity manipulation. The surgery time was the same as for group IC, but the rats were not submitted to bile duct ligature.

- Group "IC" (Icteric): N=7 animals submitted to median line incision followed by identification, exposure and ligature of the bile duct.

\section{Surgical procedure}

All surgeries were performed at the Experimental Surgery Laboratory of the Department of Surgery and Anatomy, Ribeirão Preto School of Medicine, São Paulo University.

Each animal was weighed, cleaned and anesthetized with intraperitoneal sodium thiopental. After anesthesia, the rats were positioned in dorsal decubitus and their anterior abdominal wall was shaved and disinfected with polyvinyl pyrrolidone iodine (Dermoiodine, J.P.Pharmaceutical Industry S.A. Ribeirão Preto). Access to the abdominal cavity was obtained by median laparotomy and the margins of the incision were gently separated using a delicate separator. The peritoneal cavity was maintained humid using physiological solution to avoid visceral dryness.

In the control group (SO) the animals were submitted to sham operation consisting of duodenal retraction and gentle manipulation of the biliary tract avoiding traumas.

In the jaundice group (IC), after identification and exposure of the bile duct, ligature was performed at approximately $5 \mathrm{~mm}$ from its bifurcation with five knots of prolene 5-0 suture-blue monofilament (Ethicon Inc.), involving the common bile duct up to $3 \mathrm{~mm}$ above the biliopancreatic junction, where another ligature was performed with five knots. ${ }^{9}$

On the morning of the seventh postoperative day all animals were submitted again to laparotomy over the previous surgical incision, followed by median phrenictoracotomy, identification and fast excision of the heart after sectioning of its vessels (superior and inferior vena cava, aorta artery and pulmonary artery and vein). The rats were killed by spontaneous exsanguination.

The whole heart was immediately immersed in a beaker containing $0.9 \%$ saline solution and stored inside a cooler with shaved ice to maintain the temperature between 0 and $3^{\circ} \mathrm{C}$. The atria were extracted and the ventricles were cut into small fragments of about $2 \mathrm{~mm}$. During this procedure, repeated washings were done with $0.9 \%$ saline solution at a temperature of 0 to $3^{\circ} \mathrm{C}$ in order to separate the cardiac muscle from blood and blood clots.

\section{Isolation of cardiac mitochondria}

To isolate cardiac mitochondria each ventricle was homogenized for 10 seconds with $10 \mathrm{ml}$ of $100 \mathrm{mM} \mathrm{KCl}, 50$ mMMOPS, 2 mMEDTA and $0.5 \%$ BSA, $\mathrm{pH}$ of 7,4, in Turrax. The homogenate was centrifuged at $750 \mathrm{~g}$ for 3 minutes and the resulting supernatant was again centrifuged at $15,000 \mathrm{~g}$ for 10 minutes. The pellet was suspended to the original volume using EDTA-free homogenizing medium and centrifuged at $15,000 \mathrm{~g}$ for 10 minutes. This step was repeated once. ${ }^{10}$

The velocity of mitochondrial oxygen consumption in stages 3 and 4 was determined by the 
polarographic method using an oxygraph equipped with a Clarck electrode at $30^{\circ} \mathrm{C}$. Mitochondrial oxygen consumption was determined by the velocity of stage 3 which reflects the mitochondrial capacity of producing energy. Velocity of stage 4 records the consumption of oxygen by energized mitochondria in the absence of ADP. The RCR was obtained by the ratio of stage 3 to stage 4 .

Statistical analysis was performed using the MannWhitney test, with the level of significance set at $5 \%$ $(\mathrm{p}<0.05)$.

\section{Results}

The results obtained in the present study are summarized in the figures below.

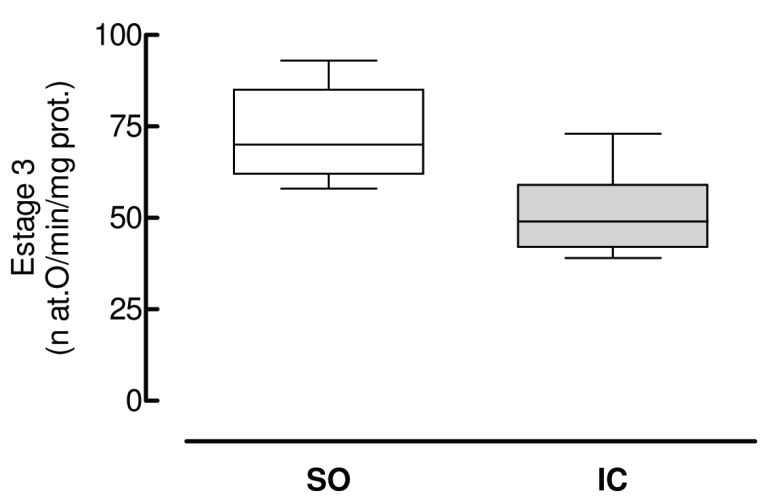

FIGURE 1 - Oxygen consumption for stage 3 mitochondrial respiration expressed as $\mathrm{n}$ atoms/ oxygen/minute/mg of mitochondrial protein for the two groups studied: $\mathrm{SO}(72.7 \pm 12.5)$ and IC ( $51.6 \pm 11.4)$. Group SO vs Group IC (p<0.01).

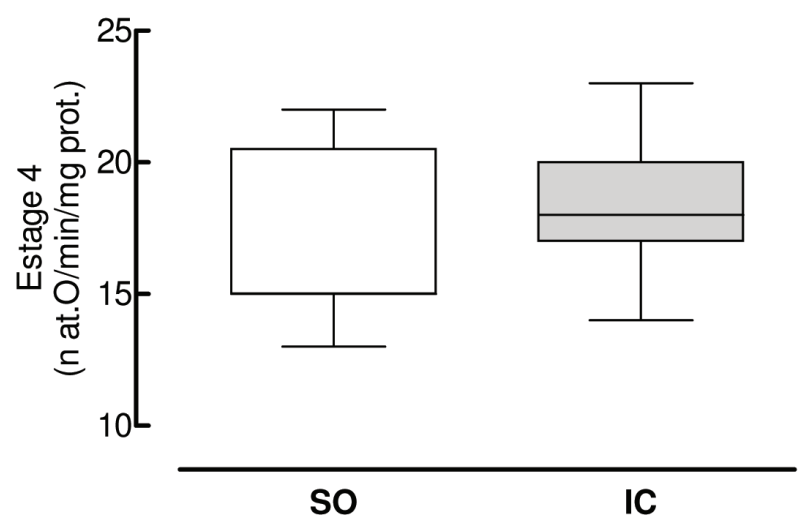

FIGURE 2 - Oxygen consumption for stage 4 mitochondrial respiration expressed as $\mathrm{n}$ atoms/ oxygen/minute/mg of mitochondrial protein for both groups studied: SO $(17.2 \pm 3.3)$ and IC $(18.1 \pm 2.8)$. Group SO vs Group IC ( $\mathbf{p}>0.05$ ).
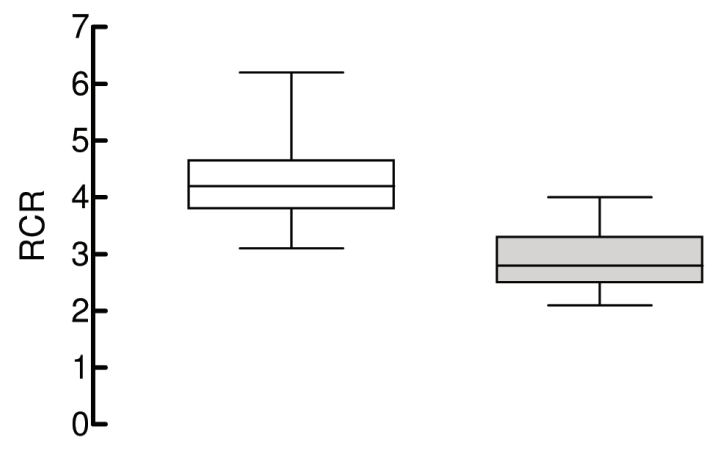

so

IC

FIGURE 3 - Respiratory control ratio (RCR) for both groups studied: SO $(4.3 \pm 0.83)$ and IC ( 2.8 $\pm 0.64)$. Group SO vs Group IC $(\mathbf{p}<\mathbf{0 . 0 1})$.

\section{Discussion}

Obstructive jaundice secondary to extrahepatic biliary obstruction is a common clinical condition caused by biliary lithiasis, traumatic and inflammatory stenosis, extrinsic compression and tumors in the biliary tree, papilla, pancreas and duodenum. Chronic cholestasis can culminate in biliary fibrosis and cirrhosis, portal hypertension and hepatocellular failure. ${ }^{1}$

The time lag between initial biliary obstruction and the appearance of cirrhosis varies widely from two months for patients with biliary obstruction resulting from tumors up to seven years for biliary obstruction of benign etiology..$^{9,11,12}$

As demonstrated for the evolution of chronic jaundice to biliary cirrhosis and hepatocellular failure, isolated clinical cholestasis is a condition favoring serious complications such as postoperative shock and renal failure. $^{7}$

Patients submitted to surgery because of obstructive jaundice present a high incidence of morbidity and mortality due to postoperative renal insufficiency. A review of different series revealed a general mortality index of 16 to $18 \%$ in patients submitted to surgery because of obstructive jaundice. Acute renal insufficiency occurs in approximately 8 to $10 \%$ of these individuals and contributes to mortality in 70 to $80 \%$ of cases. ${ }^{2,5}$

These individuals are more succeptible to hemorragic shock than non-jaundiced patients, probably because of lower basal arterial pressure levels and an attenuated response of the cardiovascular system to sympathomymetic stimulation. In view of these observations, a cardiovascular dysfunction model was suggested as an etiologic factor in the pathogenesis of postoperative renal failure in jaundiced patients. ${ }^{13}$

Hepatic illness and obstructive jaundice cause vasodilatation and a diminished pressor response to many vasoactive agents. Green and collaborators ${ }^{7}$ studied the effect of jaundice on left ventricular function in dogs submitted to choledochocaval anastomosis and observed 
a reduction in left ventricular performance evidenced by the decrease of maximum peak pressure of the left ventricle and an increase of systolic interval. A prolonged preejection period and diminished left ventricular ejection time was observed, with no alteration in electromechanical systolic activity. In the present study, mean arterial pressure and cardiac output did not differ significantly between groups, a fact that might be explained by the reduced post-load due to peripheral vasodilatation observed in the jaundiced group. Thus, reduction of peripheral vascular resistance may disguise a lingering cardiac dysfunction that can be evidenced by more sensitive indexes of cardiac function analysis. ${ }^{7}$

In 1956, Zollinger and Williams observed, independent of one another, that jaundiced patients submitted to biliary tract surgeries were more succeptible to shock and renal insufficiency after hemorrhagic events occurring during surgery. The same authors suggested that extracellular volume expansion prior to surgery would lessen the susceptibility of jaundiced patient to hypotension. ${ }^{5}$ Since then, many studies have been performed in order to understand the effects of jaundice on predisposition to hemorrhagic shock. Williams and collaborators $^{3}$ observed a $44 \%$ mortality rate for dogs submitted to chronic bile duct ligature and then to hemorrhagic shock compared to control, and the amount of blood required to lower the mean arterial pressure to 66 $\mathrm{mmHg}$ in animals submitted to chronic bile duct ligature was half the amount required for the control group. ${ }^{3}$

Alon and collaborators, ${ }^{14}$ using choledochocaval anastomosis as an experimental model in dogs, demonstrated the development of hypotension and reduced peripheral resistance. The tendency to hypotension was associated with a reduced response to vasoactive agents and to volemic expansion. The vasodepressor effects of bile components have been demonstrated in in vitro studies. ${ }^{14,15}$ Jacob et al., ${ }^{16}$ looking for the cellular mechanism responsible for the reduced vascular response during experimental cholestasis, detected a dysfunction in the expression of vascular alpha1 adrenoreceptors which was present both in vitro and in vivo. Thus, the authors concluded that obstructive jaundice induced diminished peripheral vascular resistance irrespective of whether the patient presented volume depletion, along with an exaggerated hypotensive response to blood loss. ${ }^{16}$

The mechanism of action of bile salts is not restricted to effects on peripheral vessels but their negative chronotropic and inotropic effects on cardiac muscle have been known for over a century. ${ }^{17,18}$

Binah et al. ${ }^{19}$ demonstrated negative chronotropism related to biliary acids in rat papillary muscles and isolated ventricular myocytes. This effect was attributed to the suppression of slow calcium influx through the cell membrane resulting in reduced duration of the action potential.

In contrast, in animals with chronic ligature of the bile duct, cardiac output was normal or even increased. However, overall cardiac output is not sufficient to detect latent or preclinical cardiomyopathy, with more sensitive markers of left ventricular contractility being needed for this purpose. On this basis, Green et al., ${ }^{7}$ after studying dogs submitted to choledochocaval anastomosis, observed a reduction in left ventricular performance demonstrated by the decreased maximum pressure peak of the left ventricle, prolonged pre-ejection period and reduced left ventricular ejection time compared with nonjaundiced dogs. Additionally, ventricular muscle isolated from jaundiced dogs was found to be refractory to isoproterenol. Hence, jaundice induces a cardiomyopathy whose most probable cause is intracellular myocyte glycogen depletion associated with deficient energy metabolism. ${ }^{7}$ Ramond et al. ${ }^{20}$ demonstrated reduced inotropism and chronotropism after catecholamine infusion in cirrhotic patients due to down-regulation of myocardial beta-adrenergic receptors.

The reports cited above support the observation of the clinical susceptibility of jaundiced patients to postoperative shock, as well as the hypothetical existence of a sub-clinical cardiomyopathy contributing to the development of circulatory failure associated with cholestasis.

In addition to promoting functional and metabolic derangement in cardiac muscle, would bile salts be able to alter myocardial ultrastructure? Ludatscher et al. ${ }^{21}$ studied myocardial ultrastructure in jaundiced dogs after chronic ligature of the common bile duct or choledochocaval anastomosis, analyzing the left ventricular myocardium and the papillary muscle. No significant difference in sarcomere length or mitochondrial density was observed between dogs with or without jaundice. No sign of cardiac cell hypertrophy, no difference in lipofuchsin corpuscles or other lysosomal corpuscles was detected in the two groups, demonstrating that myocardial cell structure was preserved and that biliary salt dysfunction occurred at the molecular level. $^{21}$

The main function of cardiac muscle is to maintain cardiac output, which in turn is dependent on systolic volume and heart rate. Systolic volume is influenced by preload, post-load and cardiac inotropism. ATP (adenosine triphosphate), the basic energy substrate for muscle contraction, is produced by mitochondrial respiration using ADP (adenosine diphosphate) and phosphate as oxidizable substrates through oxygen consumption. Could cellular respiration, the basic molecular function for the proper performance of cardiac muscle, be altered or even depressed in the jaundiced patient?

Mitochondrial capacity to synthesize ATP is known as mitochondrial respiration, which occurs by means of an electron transport chain and by oxidative phosphorylation. The electrons, originating from intermediates of tricarboxylic acids, flow along a chain composed of electron transport multienzymatic complexes which successively extract energy from them until their final delivery to molecular oxygen, the terminal electron acceptor. During this process, the greater share of energy is stored as ATP due to oxidative phosphorylation. ${ }^{22}$

Stage 3 respiration can be defined as oxygen consumption for the synthesis of ATP from ADP. Stage 4 respiration refers to basal respiration when ATP is already 
synthesized. RCR, consisting of the ratio between the velocity of stage 3 and stage 4 , is an indicator of the extent of coupling between electron transport and oxidative phosphorylation, which shows how intact the internal membrane is after mitochondrial isolation. ${ }^{23,24}$

In the present study, the stage 3 respiration of group IC was reduced compared with SO (Figure 1). Knowing that stage 3 involves activated respiration and thus oxygen consumption to form ATP from ADP, it may be concluded that cardiac myocyte impregnation by bile salts causes diminished oxygen consumption in stage 3, compromising the efficiency of ATP synthesis.

Extra-hepatic cholestasis did not alter oxygen consumption in stage 4 (basal respiration), with practically no differences between groups (Figure 2). Basal respiration also reflects the function of internal membrane permeability, responsible for the maintenance of the proton gradient observed when the membrane is energized. Thus, it is reasonable to assume that cholestasis alone does not change mitochondrial membrane permeability.

However, RCR differed significantly between the IC and SO groups (Figure 3). RCR is the index most extensively used to express mitochondrial quality. As demonstrated by the reduced RCR values of the IC group, there was mitochondrial impairment and alteration of the cellular energy process in the cardiac myocytes of jaundiced rats.

Analysis of the results revealed that biliary obstruction reduced RCR because of stage 3, without interfering with stage 4 ; additionally, jaundice did not modify the physical status of the internal mitochondrial membrane, preserving permeability and proton potential, but with a significant reduction of oxygen consumption as shown by the reduction of stage 3 and RCR values. These events led us to conclude that cardiac cell impregnation with bile salts provokes a reduced energy potential at the expense of mitochondrial respiration (oxidative phosphorylation), among other factors.

\section{Conclusion}

We may conclude that the cellular respiration of the "jaundiced heart" is depressed, supporting the idea of a latent cardiac impairment responsible for the hemodynamic decompensation occurring during cholestasis.

\section{References}

1. Zimmermann H, Reichen J, Zimmermann A, Sagesser H, Tenisch B, Hoflin F. Reversibility of secondary biliary fibrosis by biliodigestive anastomosis in the rat. Gastroenterology.1992;103:579-89.

2. Dixon JM, Armstrong CP, Duffy SW, Davies GC. Factors affecting morbidity and mortality after surgery for obstructive jaundice: A review of 373 patients. Gut. 1983;24:845-52.

3. Williams RD, Elliot DW, Zollinger RM. The effect of hypotension in obstructive jaundice. Arch Surg. 1960;81:334-40.

4. Walker JG. Renal failure in jaundice. Proc R Soc Med. 1962;55:570-4
5. Green J, Better OS. Systemic hypotension and renal failure in obstructive jaundice - mechanistic and therapeutic aspects. J Am Soc Nephrol. 1995;5:185371.

6. Binat O, Bomzon A, Blendis LM, Mordohovich D, Better SO. Obstructive jaundice blunts myocardial contractile response to isoprenaline in dogs: a clue to the susceptibility of jaundiced patients to shock? Clin Sci. 1985;69:647-53.

7. Green J, Beyar R, Sideman S, Mordechovitz D, Better OS. The "jaundiced heart": a possible explanation for postoperative shock in obstructive jaundice. Surgery. 1986;100:14-20.

8. Tajuddin M, Tariq M, Bilgrami NI, Kumar S. Biochemical and pathological changes in the heart following bile duct ligation. Adv Myocardiol. 1980;12:209-12.

9. Castro e Silva Jr O, Mazzeto AS, Santos JS, Ceneviva R, Zucoloto S. Experimental induction of secondary biliary cirrhosis in rats. A new surgical procedure. Res Surg. 1995;7:42-4.

10. Uyemura SA, Jordani MC, Polizello ACM, Curti C. Heart FoF1-ATPase changes during the acute phase of Trypanosoma cruzi infection in rats. Mol Cell Biochem. 1996;165:127-33.

11. Santos JS, Ceneviva R, Castro e Silva Jr O, Salgado Jr W, Garcia AMC. Evolução da cirrose biliar secundária após derivação bilioduodenal em ratos. Acta Cir Bras. 1996;s1:45-8.

12. Santos JS, Ceneviva R, Castro e Silva Jr O, Zucoloto S, Cabrera AM. Evolution of secondary bile cirrhosis by comparing the effects of bilioduodenal and biliojejunal shunts. Digestion. 1998;59:554.

13. Jacob G, Nassar N, Hayam G, Ben-Haim S, Edoute Y, Better OS, Bomzon A. Cardiac function and responsiveness to beta-adrenoceptor agonists in rats with obstructive jaundice. Am J Physiol. 1993;265 (2 Pt 1):G314-20.

14. Alon U, Berant M, Mordechovitz D, Hashmonai M, Better OS. Effect of isolated cholaemia on systemic haemodynamics and kidney function in conscious dogs. Clin Sci. 1984;63:59-64.

15. Bomzon A, Finberg JPM, Tovbin D, Naidu SG, Better OS. Bile salts, hypotension and obstructive jaundice. Clin Sci. 1984;67:177-83.

16. Jacob G, Said O, Finberg J, Bomzon A. Peripheral vascular neuroeffector mechanisms in experimental cholestasis. Am J Physiol. 1993;265:G579-86.

17. Joubert P. Cholic acid and the heart: in vitro studies of the effect on heart rate and myocardial contractility in the rat. Clin Exp Pharmacol Physiol. 1978;5:9-16.

18. Joubert P. An in vivo investigation of the negative chronotropic effect of cholic acid in the rat. Clin Exp Pharmacol Physiol. 1978;5:1-8.

19. Binat O, Rubinstein I, Bomzon A, Better OS. Effects of bile acids on ventricular muscle contraction and electrophysiological properties. Studies in rat papillary muscle and isolated ventricular myocytes. Arch Pharmacol. 1987;335:160-5.

20. Ramond MJ, Comoy E, Lebrec D. Alterations in isoprenaline sensitivity in patients with cirrhosis: evidence of abnormality of the sympathetic nervous system. Br J Clin Pharmacol. 1986;21:191-6.

21. Ludatscher RM, Binah O, Bomzon A, Better OS, Lichtig C. Ultrastructure of the myocardium in dogs with induced jaundice. Acta Anat. 1987;130:242-6.

22. Castro e Silva Jr O. Função mitocondrial do fígado durante a obstrução biliar extra-hepática e após drenagem cirúrgica das vias biliares. Efeito da clorpromazina. Tese de Doutorado. Faculdade de Medicina de Ribeirão Preto da Universidade de São Paulo, 1986. 
23. Castro e Silva Jr O, Souza M E J. Ciclo de Krebs e a função mitocondrial. In: Castro e Silva Jr O, Zucoloto $\mathrm{S}$, Beer Jr A. Modelos experimentais de pesquisa em cirurgia. 1ed. São Paulo: Robe Editorial; 1998. p146-8.
24. Curti C, Uyemura S A. Estudos da fosforilação oxidativa. In: Castro e Silva Jr O, Zucoloto S,

Beer Jr A. Modelos experimentais de pesquisa em cirurgia. 1ed. São Paulo: Robe Editorial; 1998. p150-8.

\section{Correspondence:}

Rafael Kemp

Department of Surgery and Anatomy

Ribeirão Preto Faculty of Medicine, University of São Paulo

Av. Bandeirantes 3900,

Conflict of interest: none

14048-900 Ribeirão Preto, SP, Brazil

Phone: +55 163602-2593

rafaelkemp@terra.com.br

\section{How to cite the article:}

Kemp R, Castro-e-Silva O, Santos JS, Sankarankutty AK, Correa RB, Baldo CF, Souza MEJ, Jordani MC. Evaluation of the cardiac myocytes mitochondrial respiration in rats submitted to mechanical biliary duct obstruction. Acta Cir Bras. [serial on the Internet] 2008; 23 Suppl 1. Available from URL: http://www.scielo.br/acb.

\section{Comments:}

Obstructive jaundice has been known to cause severe hemodynamic disturbance. Some studies were designed to assess the cardiac involvement in jaundiced patients. These studies prove that there is blunted myocardial contractile response to the inotropic stimulation in jaundiced patients. Such myocardial refractoriness to beta-1 stimulation may contribute to the susceptibility of jaundiced patients to postoperative shock and acute renal failure. The present study proposed to evaluate the myocardium capacity of energetic production through the analysis of mitochondrial respiration in rats presenting jaundice submitted to biliary duct ligature. The results permits, consistently, to conclude that cellular respiration of the "jaundiced heart" is depressed. This was made evident by the reduced capacity of cardiac mitochondria to consume oxygen and synthesize ATP, reinforcing the idea of a latent cardiac impairment responsible for the hemodynamic decompensation of these patients. The discussion is wordy, but presented all aspects known about the "jaundiced heart" and I suggest keeping it in the present form. It is mandatory to emphasize that the present investigation is original, since the search about studies involving mitochondrial respiration of myocardium affected by jaundice do not find any specific paper.

\section{Paulo Roberto Barbosa Évora}

Full Professor and Head, Division Thoracic and Cardiovascular Surgery, Department of Surgery and Anatomy, Ribeirão Preto Faculty of Medicine, University of São Paulo, Brazil.

\section{Comments:}

Propensity to higher surgical morbidity is seen in patients with obstructive icterus in addition to renal, pulmonary and cardiac complications in the post-operative. Understanding all factors involved in the increased morbidity, necessarily includes knowledge about the nature of the obstruction as well as the complications induced by billirubin and biliary salts accumulation in the organs. Lack of bile in the digestive tract favors endotoxin absorption, which join the already compromised organs by the hepatic compounds. Experimental models addressing organ functional alterations during obstructive icterus should include histological studies and evaluation of membranes and intracellular organelles in order to understand events generating post-operative complications. The study entitled "Evaluation of cardiac myocytes mitochondrial respiration in rats submitted to mechanical biliary duct obstruction" describes an altered mitochondrial function, which could unleash other intracellular alterations and functionally compromise organelles. The diminished ATP synthetic capacity observed in the study, may represent initial myocyte functional alterations. Cardiac cell incapacity of generating energy in response to trauma, could eventually explain post-operative complications observed in icteric patients.

\section{Carlos Augusto Teixeira da Cruz}

MD, Associate Professor, Clinical Surgery, Faculty of Medicine, University of Brasilia, Brazil.

\section{Comments:}

Abundant proof currently confirms the chronotropic and negative inotropic effects on the cardiac muscle by increasing blood concentrations of biliary salts. As a result the cardiac function is impaired and circulatory shock and renal failure ensues in patients losing blood during extra-hepatic cholestasis surgery. The subjacent cellular mechanism involved in the cardiac dysfunction is not fully understood although a deficient energetic metabolism is considered as one of the reasons. The utilization of ever more sensitive indexes in the study of the cardiac function is suggested by Green et al. and justifies this investigation by Kemp et al. The myocardial energetic metabolism was evaluated by an adequate method measuring oxygen consumption during myocyte mitochondrial respiration in rats submitted to extra hepatic cholestasis induced by ligature of the main biliary duct. Control rats were sham-operated. Results show that myocardial cellular respiration is depressed in the "icteric heart" as indicated by reduced oxygen consumption in activated respiration, which in turn, means mitochondrial low capacity of ATP synthesis . The integrity of the mitochondrial membrane was not disturbed. The present results surely contribute to an improved understanding of the alterations in heart energetic metabolism, as co-participants in the etiology of cardiac dysfunction during extra hepatic cholestasis.

\section{Reginaldo Ceneviva}

Full Professor, Department of Surgery and Anatomy, Ribeirão Preto Faculty of Medicine, University of São Paulo, Brazil. 